Georg A. Buchner, Kai J. Stepputat, Arno W. Zimmermann, and Reinhard Schomäcker

\title{
Specifying technology readiness levels for the chemical industry
}

Journal article | Accepted manuscript (Postprint)

This version is available at https://doi.org/10.14279/depositonce-11483

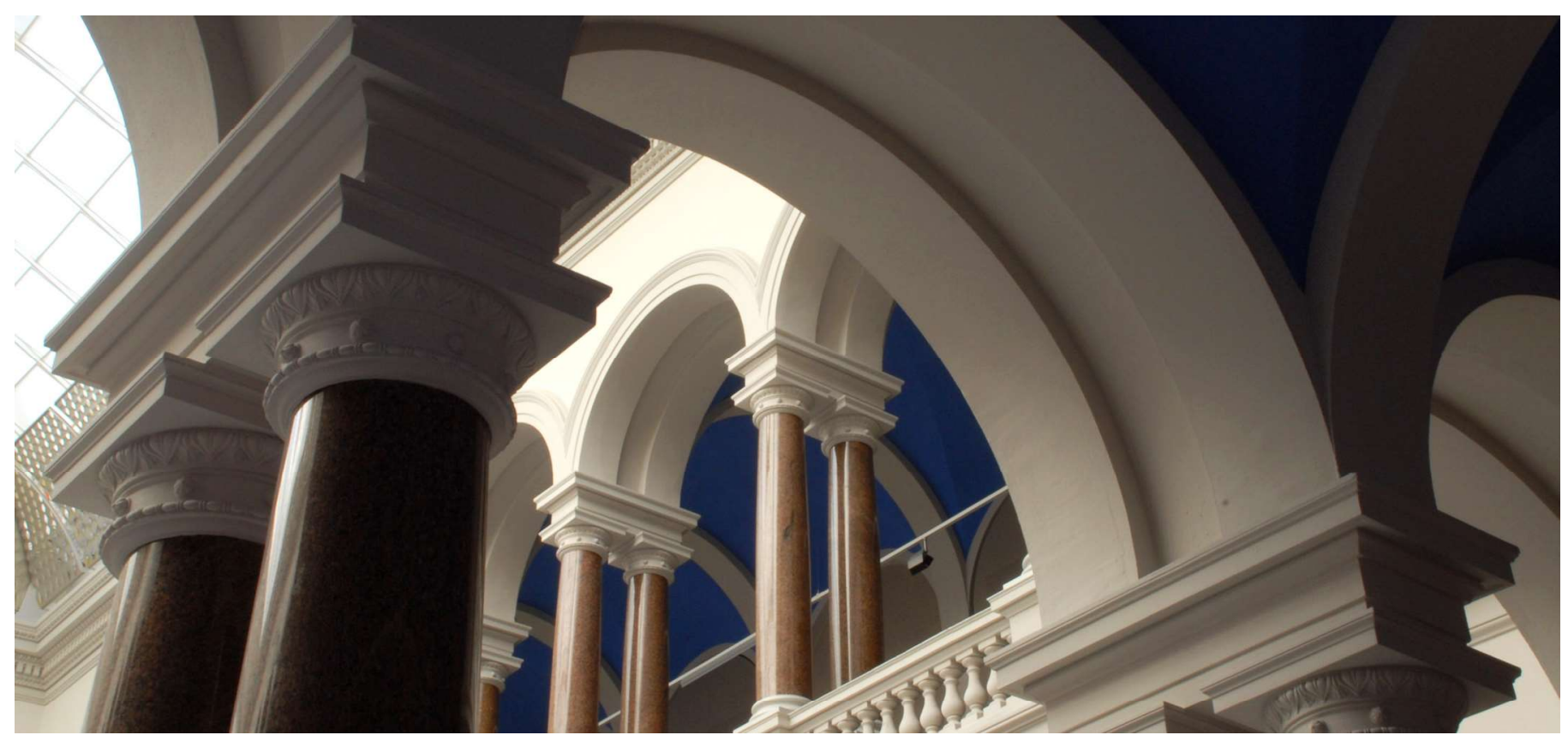

Buchner, G. A., Stepputat, K. J., Zimmermann, A. W., \& Schomäcker, R. (2019). Specifying Technology Readiness Levels for the Chemical Industry. Industrial \& Engineering Chemistry Research, 58(17), 69576969. https://doi.org/10.1021/acs.iecr.8b05693

This document is the Accepted Manuscript version of a Published Work that appeared in final form in the Journal of the American Chemical Society, copyright (c) American Chemical Society after peer review and technical editing by the publisher. To access the final edited and published work see https://pubs.acs.org/doi/10.1021/acs.iecr.8b05693. 


\section{Specifying Technology Readiness Levels (TRL) for the Chemical Industry}

Georg A. Buchner, Kai J. Stepputat, Arno W. Zimmermann, Reinhard Schomäcker*

Technische Universität Berlin, Department of Chemistry, TU Berlin, Straße des 17. Juni 124,

10623 Berlin, Germany 


\begin{abstract}
Technology readiness levels (TRL) have received increasing recognition throughout academia, industry and policy-making as a tool for evaluating and communicating a technology's maturity. Conventional scales are unspecific to technologies as they aim at evaluating and comparing technologies combining different fields. Hence, they present vague descriptions which leave considerable room for interpretation and subjective choices. For the chemical industry, adaptions and specific criteria are needed for more comprehensible TRL ratings. This paper specifies the nine conventional TRLs for the chemical industry as: Idea, Concept, Proof of concept, Preliminary process development, Detailed process development, Pilot trials, Demonstration and full-scale engineering, Commissioning, and Production. Adjusted descriptions and additional criteria with detailed indicators are presented, depicting the logical progression of a typical chemical innovation in the phases of applied research, development and deployment. The specified TRLs facilitate evaluation and communication of a technology's maturity and substantially improve the basis for data availability-based assessment.
\end{abstract}




\section{Introduction}

The evaluation of a technology's maturity receives increasing recognition among stakeholders throughout academia, industry and policy-making that strive to achieve more efficient use of resources such as capital, material or infrastructure. In the chemical industry, the time required for an innovation to pass from ideation to commercialization is relatively long compared to other fields of industry (up to about ten years). Reducing the time for an innovation to get marketready holds high potential for lowering costs or getting major competitive advantages and leads companies to rethink their innovation strategies ${ }^{1}$. This raises the demand for an accurate way of evaluating and a comprehensible way of communicating the current status of an innovation and better overall understanding of maturity stages of a technology in research, development or deployment (RD\&D). Only if the current maturity of a technology is well known, adequate measures can be concluded and undertaken. These measures include future development tasks and related supporting activities such as project management, risk analysis or marketing; as well as decision-making. For example, in earlier stages, more effort is typically directed towards analyzing a variety of process alternatives instead of external communication; as another example, decision-makers shift their focus from excluding technologies that do not stand a chance of being viable early on to selecting the single most promising process for implementation in advanced stages. Following the evaluation of technology maturity, practitioners can reduce uncertainty by adequate assessment or disclosing issues like deficits and problems in the respective development $\operatorname{project}^{2-4}$.

A popular concept for the evaluation of technology maturity is the concept of rating its readiness for a certain purpose in levels, called 'technology readiness levels (TRL)'. The first scale, showing seven levels, was created by NASA researcher Stan Sadin in $1974^{5}$. The concept was 
initially developed for space exploration, a domain that integrates a variety of disciplines from mechanical, electrical and chemical engineering to aviation, medicine and computer science. The NASA scale was extended to nine levels in 1995 by John Mankins ${ }^{2}$. Since then, a variety of scales (including amendments by NASA, extended descriptions ${ }^{6}$ as well as separation into software, hardware and exit criteria ${ }^{7}$ ) evolved. Most presented scales incorporate nine distinct levels. Some scales present adaptions to specific technology fields such as energy ${ }^{8}$, steelmaking ${ }^{3}$, health-care ${ }^{9}$ or biotechnology ${ }^{10}$ (an exhaustive list is outside the scope of this paper). Overall, TRLs enable the comparison of technologies (benchmarking) ${ }^{11}$ across different audiences as they constitute a common understanding and way of communicating technologies ${ }^{4,12}$. The most influential scales and the scales most commonly used in the chemical industry are summarized in Table 1. A compilation of these scales with TRL titles and further descriptions is given as supporting information S1. 
Table 1: Popular and influential TRL scales, issuing institutions and description of the scales'

purposes

Issuing institution

US National Aeronautics and Space Administration

$(\mathrm{NASA})^{2,6,7}$

US Department of Defense

$(\mathrm{US} \text { DoD })^{13}$

US Department of Energy

$(\mathrm{US} \text { DoE })^{8}$

US Department of Health and Human Services

(US HHS $)^{9}$

European Commission, horizon 2020 framework

$(\mathrm{H} 2020)^{14}$

European Association of Research and Technology Organizations

$(\text { EARTO })^{4}$

NSF Engineering Research Center for Biorenewable Chemicals

$(\mathrm{CBiRC})^{10}$

International Organization for
Standardization, standard 16290

$(\text { ISO 16290) })^{15}$

European Space Agency

$(\mathrm{ESA})^{16}$
Purpose and background of the scale

Space technology planning as a measurement system that "supports assessments of the maturity of a particular technology and the consistent comparison of maturity between different types of technology"2

Focus on "critical technologies"13, used in 'Major Defense Acquisition Programs', evaluates the degree of risk associated with each TRL and recommends mitigation measures

Based on NASA and US DoD, adapted to DoE needs, incorporates scale of testing, system fidelity and environment (waste) as criteria in the description, provides appendix with questions for general TRL rating and detailed questions for critical technical elements

Biomedical adaption: designed for evaluating the maturity of medical countermeasure products (drugs and biologics)

Brief TRL definitions, TRLs are used to ensure that funded projects cover the full range of RD\&D activities, setting up of funding programs and monitoring of the progress of funded projects

Based on H2020 scale, extended with EARTO readings and descriptions, used as research \& innovation policy tool: designed to help design funding tools and policies as well as help single funding decisions (by governments)

NASA scale adapted to bio-based research and manufacturing

Based on the NASA, DoD and European space institutions scales, primarily applicable to space system hardware, including titles, descriptions and examples

Very similar to the NASA scale, incorporating ISO $16290^{15}$, providing data requirements for each TRL 
Despite their established application in the chemical industry, the aforementioned scales often do not meet the requirements of practitioners concerning objectiveness and comprehensible rating $\left(\right.$ see also ${ }^{4,17}$ ). This is for several reasons which are addressed with this paper:

Most notably, established TRL scales lack detailed indicators. The general need for more specific TRL scales was reported by EARTO ${ }^{4}$ and exemplified for the steel industry by Klar et $a l .^{3}$, who report differences of up to two TRLs when applying non-specific TRL scales ${ }^{3}$. Regarding specification, the following general trade-off was identified: Unspecific TRL scales can serve a variety of different technologies and make them comparable. At the same time, the rating of each single technology remains vague due to the lack of specific criteria and indicators. Conversely, more specific indicators enable more accurate TRL rating; however, they narrow down the range of technologies the scale is applicable for. Currently existing scales often cover a variety of technologies and thus present vague indicators that leave room for interpretation and subjective choices when applied in the chemical industry. Consequently, such TRL ratings are prone to subjective evaluation and are difficult to reproduce. Criteria and indicators specific for the chemical industry are expected to lead to more comprehensible rating. However, specification is inherently only possible when addressing selected technology fields (e.g. chemicals in general) or even groups within the field (e.g. base chemicals, rubbers, additives), limiting the versatility of the TRL scale. Adaptions to other technology fields have been presented, yet they mostly cover altered titles and descriptions without providing further details of the TRLs (e.g. ${ }^{3,12,18}$, also see Table 1). This paper targets more accurate and comprehensible TRL rating by presenting specific criteria and indicators.

In order to tailor TRL scales to the chemical industry, characteristics of this field need to be considered in the specified scale. This becomes especially evident in view of the terminology 
that conventional scales use, which lacks meaning in the chemical industry or is difficult to adapt: Prominent examples are the terms 'prototype'12,19, 'environment' ${ }^{12,20}$, and 'demonstration"21. The word 'prototype' whose meaning as "a first full-scale and usually functional form of a new type or design of a construction" ${ }^{\text {"22 }}$ is easily understood in mechanical engineering but lacks a common interpretation in chemical industry research, development and deployment. Testing a technology in different 'environments' - if understood as natural surroundings such as soil or weather conditions - is not an intuitive idea for chemical plants due to their general immobility. The broad term 'demonstration', meaning an "act of showing that something exists or is true by giving proof or evidence"23, requires specification with regard to what is demonstrated to whom. The TRL understanding recently reported by Humbird ${ }^{24}$ is focused on the bioeconomy with limited validity for the non-biologic process industry. The here presented framework makes use of concepts applicable in the whole chemical industry.

Moreover, past approaches did not develop TRL scales in a transparent and systematic intersubjective way and lack explicit definitions of all concepts used and distinction of methods applied (e.g. some established TRL scales represent single experts' opinions). Major characteristics of TRL scales such as the meaning of 'readiness', beginning and end of a TRL scale or tiers of TRL rating regarding technology elements remain largely absent from both popular TRL concepts' descriptions and scientific discussions up to this point. Methodological considerations as shown in this paper are needed in order to yield an intersubjective understanding and make sure that the TRL scale can be applied beneficially in the chemical industry.

In addition to the uncertainty resulting from different interpretations of one particular scale at hand, there are a variety of different scales available that introduce another source of uncertainty 
of a reported TRL, especially if the underlying scale is not stated along with the rating. This paper does not present a new concept that is contrary to established scales. Rather, for a single field of technologies, the chemical industry, it suggests a common interpretation of the established TRL scales through specification and aims to facilitate the process of agreeing on a common understanding of TRLs.

This paper builds on earlier work ${ }^{17,20,25}$ which was done in the context of improving technology assessment methodology, more specifically techno-economic assessment (TEA). Adequate methods for TEA change with the level of data available. TRLs represent development progress which is closely linked to data availability. As a consequence, TRL-based assessment was recently introduced for the chemical industry ${ }^{17,19,20,25,26}$, including efforts to connect the TRL concept explicitly to research, development and deployment in the chemical industry. However, previous efforts were limited to a) basic principles of TRLs in the chemical industry and b) rating by means of general project criteria - with the sole intent to yield a model for stages of data availability. Advancing the scientific understanding of the TRL concept itself as well as improvements and extensions were left to future research and are addressed in this paper, which builds on the ideas previously presented and thereby aims at providing a more solid foundation for TRL-based assessment.

This paper's structure reflects the procedure and order of questions asked when specifying TRLs for the chemical industry: Chapter 2 shows characteristics of TRL scales in general and how they can be adapted to the chemical industry. It is opened by introducing basic terminology and concepts (2.1) and followed by the main questions of; first, what the beginning and end of the TRL scale are (2.2) and second, how levels are characterized (2.3). Then, possible and applied methodology for level differentiation is described (2.4). Specific perspectives of target groups on 
TRL rating are described in the following (2.5 and 2.6). Chapter 3 presents the specified TRL scale. The TRLs are aligned with innovation phase concepts (3.1), the selected criteria are described (3.2), and detailed indicators shown (3.3). Chapter 4 explains how the scale is used for TRL rating (4.1) and what tasks may follow (4.2). This paper closes with a critical review and outlook (5).

\section{Adapting TRL scales to the chemical industry \\ 2.1 Terminology and concepts}

One challenge when specifying TRLs for the chemical industry lies within the commonly used concepts that can have different meanings to practitioners. As the set up scale incorporates and relies on those concepts, brief descriptions are given in the following:

Maturity and readiness. Maturity is described as "the quality or state of being mature"27, with "mature" as "having attained a final or desired state" 28 . Readiness is described as "the quality or state of being ready: such as [...] a state of preparation" 29 for a targeted use. Whereas 'maturity' can be understood as a state that is either true or false, the concept of 'readiness' introduces graduation. In literature, there is no clear distinction between 'maturity' and 'readiness' when used in technology maturity rating with technology readiness levels; both terms are used interchangeably.

Technology and technology element: A 'technology' is seen as an "application of scientific knowledge for a practical purpose" 30 and 'technology element' being a 'a distinguishable part of technology' which can for example be "a unit process, a unit operation or a piece of equipment"17.

Criterion and indicator. In general, a 'criterion' is seen as a "condition that need[s] to be met in order to adhere to a principle" ${ }^{31}$. In this paper, this concept is applied in two ways: First, an 
aspect that helps to set up requirements for beginning and end of the scale. Second, an aspect that helps to rate how far advanced a technology is by judging the states of indicators for a given TRL (i.e. a row in Table 2, similarly ${ }^{12}$ ). In accordance, 'indicators' are variables with measurable states that reflect the state of an associated criterion $^{31}$ (i.e. a cell entry in Table 2).

Rating $v S$. assessment. The term 'TRL rating' is preferred over 'TRL assessment' as the question of how mature or ready a technology is, can be answered with the analysis of its current characteristics and does not include a judgement in terms of good or bad ${ }^{20}$.

Plant types. In the chemical industry, innovation progress is often related to different plant types that enable the collection of additional information ${ }^{32}$. However, understandings in literature differ. For this paper, distinguishing between plant types is predominantly about the task that a specific plant has to fulfill rather than its size or capacity (see also ${ }^{24,33-36}$ ). Figure 1 shows typical tasks and goals of different plant types and further characteristic elements. The capacity normally increases as a consequence of the tasks in the order shown. 


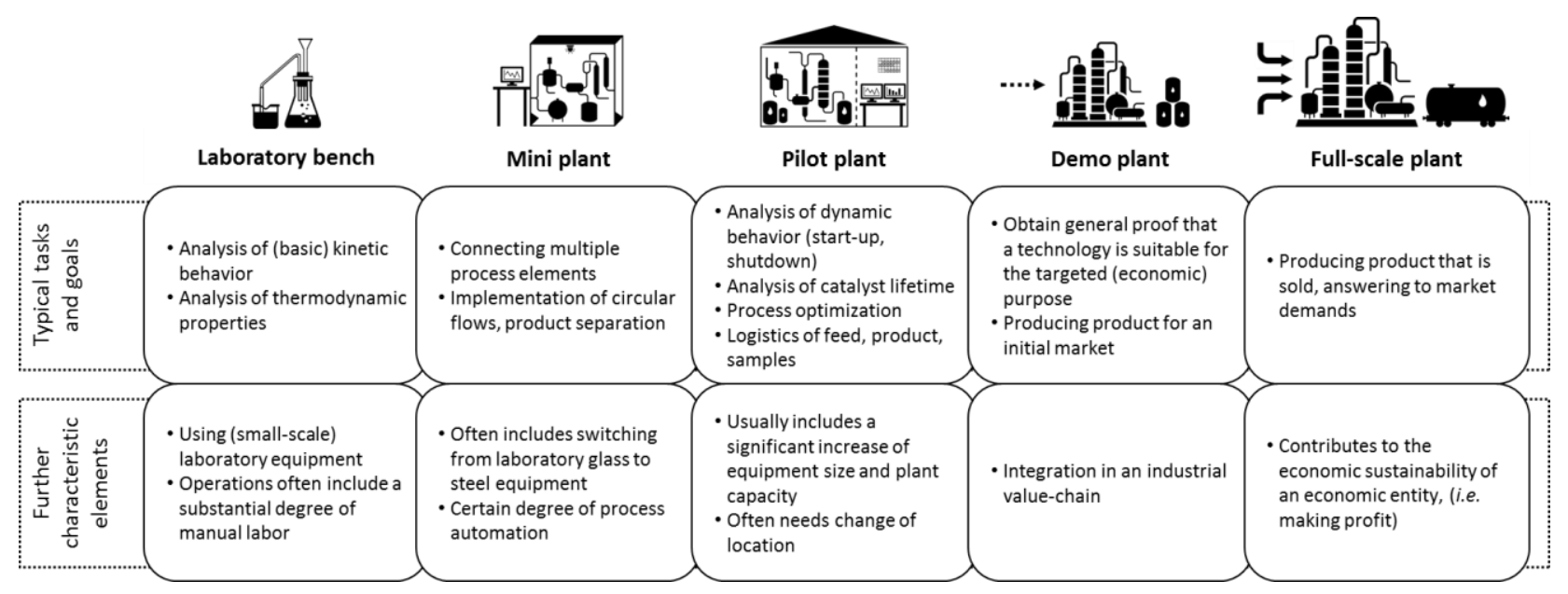

Figure 1: Typical tasks, goals and further characteristics of different plant types within the chemical (or process) industry

Innovation phases. After basic research, the stages an innovation passes through can be separated into applied research, development and deployment (see also ${ }^{37,38}$ ). Basic research focuses on understanding natural phenomena and does not target the introduction of a technology ${ }^{39}$. It is therefore, in this paper, not considered to be an innovation phase. In contrast to basic research, applied research focuses on altering understood natural phenomena in order to achieve a certain outcome ${ }^{40}$. The term 'development' describes the conversion of research into 'the creation of new and/or improved products and processes ${ }^{40}$. Applied research and development are subsumed under the abbreviation 'R\&D'. Development thus answers questions of how something can be implemented. In contrast, bringing a developed technology into effective action in an environment with a tangible result is called 'deployment' in this work (see also ${ }^{41}$ ). 
Deployment thus describes that something is implemented. Applied research, development and deployment are hereafter together abbreviated as 'RD\&D'.

\subsection{Beginning and end of the TRL scale}

The scale should intrinsically depict the level of knowledge available about the technology as it reflects its maturity. However, the beginning and end of the scale can not be determined by technical means alone as there is no objective understanding of beginning and end of general technological progress.

Some publications see TRL 1 as basic research (e.g. 10,24,42). In other descriptions (e.g. $2,4,8,9,13,14,16$ ), for TRL 1 , it is required to at least begin to translate scientific research into applied research. This translation can only be started if ideas for a technology are present - which are representations of thoughts about how understood natural phenomena can contribute to achieving a desired outcome and thus steer research towards the desired application. It can be concluded that achieving TRL 1 in the abovementioned scales includes a completed technology ideation. In the 2013 revision of the NASA scale, a published concept of an application is required ${ }^{7}$. Since basic research is not driven by the desire for technology innovation but about understanding natural phenomena, it can eo ipso not be completed and it is not suitable to be a state of a technology. We therefore adopt the perspective that TRL scales should start with ideas for a technology. Consequently, basic research refers to activities carried out prior to the TRL scale and TRL 1 is a stage of applied research.

Maturity and readiness are not objective concepts with an absolute understanding but can only be understood when placed in context. Therefore, the general question "Is the technology mature?" is replaced with "Is the technology mature enough so that it can be used for [purpose 'X']?" or, 
after introducing graduation, "To what degree is the technology ready for [purpose ' $\mathrm{X}$ ']?". The readiness is thus evaluated in relation to its characteristics needed for the targeted use.

Criteria for beginning and end are chosen by whatever use and impact the practitioner targets: For the original NASA scale, the aim was analyzing to what degree the technology is ready to be used in space exploration missions. The beginning is thus a first idea of how "basic principles observed"2 (in basic research) can be exploited in a technology for space exploration; and the end reached when the technology was "flight proven" (i.e. proven functioning in mission operation).

Economic prospects are the most significant decision basis in the chemical industry. With this criterion, the beginning is a first idea of how basic research can be exploited in a technology for commercial use (e.g. a new reaction pathway for a chemical); the end is an implemented technology that is economically sustainable in business-relevant operation (e.g. a world-scale chemical production plant in operation).

While other criteria are possible, this paper employs the stated economic criterion as it will be most applicable in the chemical industry since its motivation for technology innovations is usually driven by economic prospects. Commercial operation as the end of a TRL scale is also reported to be TRL 9 for nuclear fuels ${ }^{12}$, recycling technologies ${ }^{43}$ or aviation ${ }^{44}$.

There can be differences in the depth of knowledge gained about running full-scale plants, depending on how long they have been operated ${ }^{45}$. For example, a technology that has been commercialized (full-scale plant built and operated) decades ago will have been studied more than a technology that was commercialized only recently. Similarly, ' $\mathrm{N}^{\text {th }}$ of a kind' plants can rely on a deeper knowledge about the technology than 'First of a kind' plants ${ }^{46-49}$. For the issue of 'first use versus extensive use of a technology', some authors discuss the introduction of 
TRL $10^{50}$ or TRL 10A following TRL 9 - as well as a possible TRL 10B for technologies that became obsolete ${ }^{45}$. In the TRL scale introduced with this paper, these learnings are not considered as for TRL 10A, they do not have an influence on whether or not the (economic) criterion is met, or for TRL 10B, the (economic) criterion does not apply anymore. If learnings lead to changes in design, the technologies are considered to be different and the TRL scale has to be passed through again. TRL rating is not possible for technologies that were rated TRL 9 but were then abandoned and disappeared from the market as those technologies are not mature (with regard to the economic criterion) and not in RD\&D phases. The commercial product life cycle (e.g. explained in $\left.{ }^{51-53}\right)$ is not mirrored in the TRL scale. Although monitoring a technology's progress with TRLs can help the analysis of why and at what point technologies fail to further mature, such discussions are not part of TRL rating itself.

The concept of readiness levels was adapted to special tasks other than general RD\&D or special purposes (criteria for end of the scale). A variety of $x R L$ scales (with ' $\mathrm{x}$ ' being a letter that represents different scales; e.g. cost readiness level, $\mathrm{CRL}^{54}$, manufacturing readiness levels, $\mathrm{MRL}^{55}$, investment readiness levels, IRL ${ }^{56}$, integration readiness level, IRL ${ }^{57}$, system readiness

level, $\mathrm{SRL}^{57}$, reuse readiness level, $\mathrm{RRL}^{58}$ ) were postulated; however, their application is often limited to specific tasks or single aspects of technologies and they are therefore not as widely used $^{57}$.

\subsection{Level characteristics}

In literature, a TRL is understood as either a period of time (phase) or a fixed state that reflects a certain level of knowledge obtained from past activities (milestone). These different perspectives can lead to differences in rating of one level. In order to avoid discussions about "Where in TRL $[\mathrm{X}]$ is the technology?" and interpretations or communications such as "early/late TRL $[\mathrm{X}]$ ", this 
paper recommends treating a TRL as a milestone. Consequently, the wording "at TRL [X]" is favored over "in TRL $[\mathrm{X}]$ " as well as past participle verb form ("[X] examined") over infinitive verb form ("examine $[\mathrm{X}]$ ") when describing requirements for an associated TRL (see also Table 2).

It is debatable whether maturity describes the level of theoretical knowledge (e.g. just being able to build a plant) or requires proof that this knowledge can be implemented into a working tangible technology (e.g. plant built). The knowledge gained by actual RD\&D leads to technology maturation; however, during implementation (at all levels), major learnings can occur. Nevertheless, it is not practical to require the practitioner to implement the whole technology on every level if, for example, parts of a plant are well-known unit operations that do not require extensive $\mathrm{R} \& \mathrm{D}$ (e.g. when the focus is on designing a new reactor, the reactor output can be a mixture that is very similar to conventional processes; in this case, designing a rectification column for product separation is still part of the newly developed technology but is often not considered an intellectually challenging task and not therefore associated with high risk). However, judging how similar the technology element which is excluded from implementation (in earlier and mid stages) is to well-known elements introduces a subjective element to the TRL rating. Furthermore, for chemical technologies, connecting technology elements can itself be a major technical challenge. For these reasons, this paper recommends including all altered technology elements in order to prove a certain level of technology readiness.

Levels should depict distinguishable milestones that are passed when gaining knowledge about a chemical technology. They should not reflect the knowledge needed for the implementation of 
these specific milestones but the knowledge needed for achieving the overall purpose instead (here: full-scale plant).

\subsection{Methodology for level differentiation}

\subsubsection{Possible approaches}

For setting up and specifying levels, different approaches are possible:

Detailing and explaining current (popular) scales. This approach includes adaption of wording to the chemical industry, explaining concepts' meanings and elaborating phrasings. In this way current (popular) scales can be filled with details and potentially restructured into clusters of aspects of technology maturation. This approach is for example applied by the scales listed in Table 1 that build on each other.

Abstraction and attribution. Literature presents best practices of engineering approaches, which can be summarized and compromised to derive a common literature understanding. This approach can be based on scientific literature as well as standard textbooks $\left(\right.$ e.g. $\left.{ }^{34,59,60}\right)$ as well as expert interviews and the authors' experience. A typical innovation progress will include the usual order of questions asked and be consistent across multiple engineering aspects in a way that it follows a logical progression of the RD\&D (e.g. it does not make sense to design a reactor before the heat of reaction was studied). Levels can for example be set up by first abstracting the development steps of single equipment pieces and second, attribution of the resulting abstract steps to TRLs. Figure 2 presents an example of this approach. A similar approach was conducted for example by Zimmermann \& Schomäcker ${ }^{19}$ or Klar et al. ${ }^{3}$.

Data analysis. As a third approach, reports of past RD\&D projects can be analyzed that reflect development progress as well as development steps or project milestones. However, collecting these data is a challenge due to inconsistent reporting and confidentiality. As development 
projects' progressions can vary considerably, a large data set is required in order to conclude universally valid levels. This approach could not be included in this paper; for future research, a comparison of data sets with the set up scale would be beneficial. 


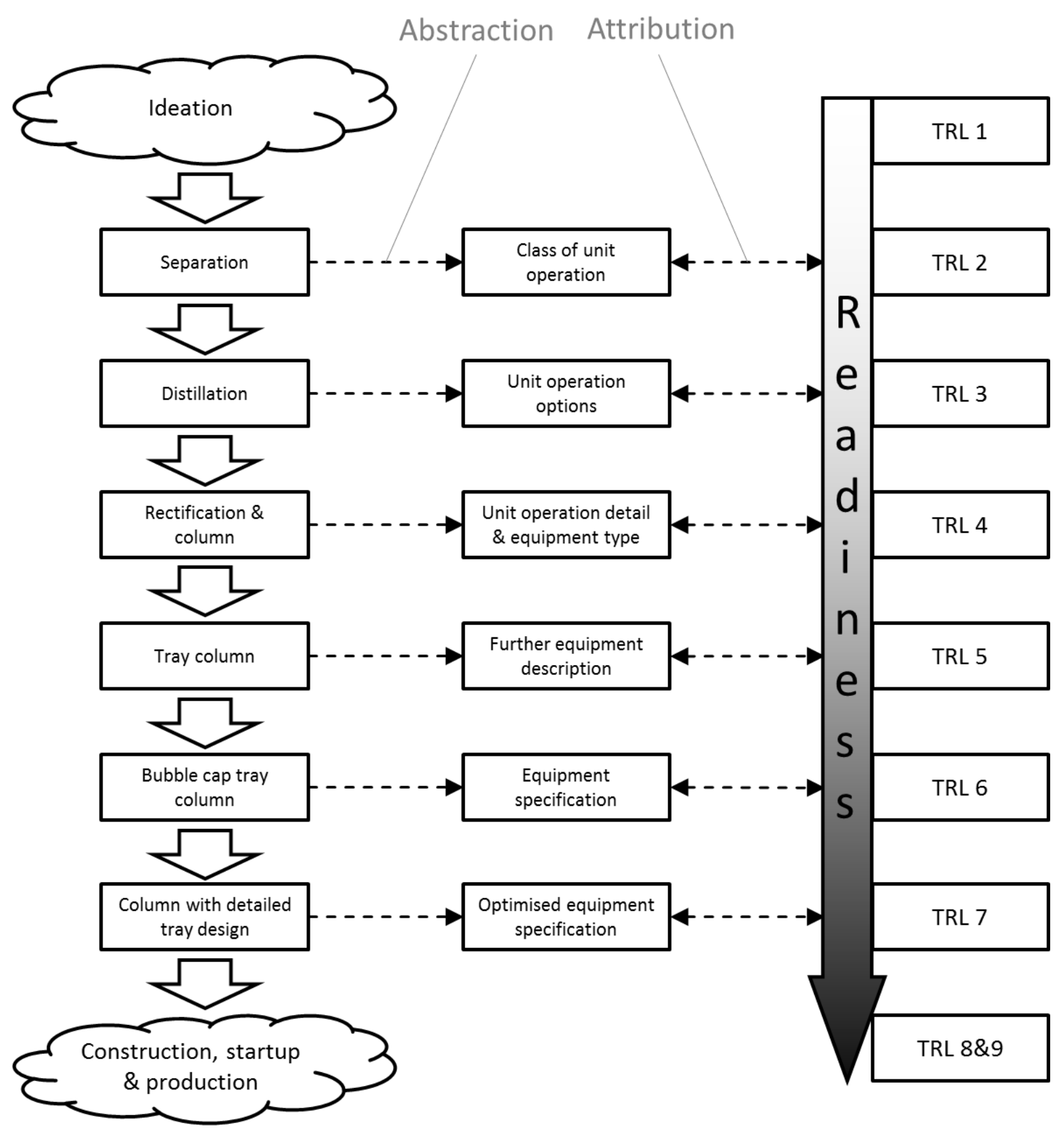

Figure 2: Abstraction and attribution to yield an understanding of TRLs in the chemical industry, example: typical RD\&D progress for a separation step in a bubble cap tray column 


\subsubsection{Applied methodology}

In this work, the general idea and frame of the scale was taken from a compilation and comparison of established scales as a starting point (see also supporting information Table S1). Level criteria and indicators were developed by concurrent a) abstraction and attribution as described above, based on engineering best practices presented in literature and b) semistructured face-to-face interviews (similarly in ${ }^{3,18,57,61}$ ) with 15 selected experts (Germany) representing different stakeholders throughout academia (state-funded and private research), industry and funding institutions as well as c) informal discussions with additional experts (international) from different stakeholders. In addition to discussions about general issues of TRLs in the chemical industry, the selected experts were asked for specific criteria and indicators for TRL rating (open questions), before being asked for feedback on the so far developed details. Iteration was conducted indirectly: All interview notes were regularly consulted in the following in order to check for contradicting views and to derive majority views. Explicit contradictions to established scales (especially Table 1) were checked and adjusted. Moreover, the specified scale was applied to current RD\&D projects for consistency checks within the levels (e.g. in ${ }^{25}$ and in confidential RD\&D projects due to good data availability). It has to be noted that incorporating the abovementioned methodology can lead towards a common understanding but the exact distinction of levels and details remain subjective to a certain degree.

\subsection{Stakeholder perspectives}

There are a variety of stakeholders that take different perspectives when evaluating and communicating the maturity of a chemical technology with TRLs. Stakeholders can take an internal or an external perspective. An internal perspective is taken by stakeholders that are directly involved in chemical RD\&D projects. This mainly includes people in academia 
(especially in earlier $\mathrm{TRLs}^{44}$ ) or industry who are carrying out RD\&D such as laboratory researchers, process engineers, or project managers. For project management, TRLs are a valuable "tracking tool" 12 for analyzing at what stage their project is and how it advances through stages of innovation ${ }^{11}$. In addition, TRLs are used by managers who are not directly involved but responsible for RD\&D projects for setting up portfolios and sorting projects in the development pipeline ${ }^{45}$. An external perspective is taken by stakeholders not involved and not responsible for $\mathrm{RD} \& \mathrm{D}$, for example partners, companies subsequent in the value chain, the general public, or institutional investors. Furthermore, the development of scales by several governmental institutions shows that TRLs are a popular concept for policy makers. As risk decreases with increasing technology maturity, TRLs help to tailor funding programs to cushion risks at different levels. A prominent example is the identification of a funding gap ("valley of death" ${ }^{\prime 2}$, as explained in ${ }^{4,21,62}$ ).

\subsection{TRLs vs. EPC maturity concepts}

Deliverable maturity is a popular concept in frameworks for engineering, procurement and construction (EPC) in the process industries ${ }^{63,64}$. EPC can largely be attributed to the deployment of a technology and forms a part of an overall innovation process. In deployment stages, both deliverable maturity and technology maturity scales are employed. Although applying similar terminology, there are conceptual differences which need to be clearly addressed in order not to distort either framework: The deliverable maturity understanding focusses on the quality within a certain stage of an EPC project's definition whereas the technology maturity analyzes the status in an overarching innovation progress. EPC is seen as a stage-gate process with degrees of planning. In comparison, technology maturity is a broader framework, incorporating the evaluation of all stages of applied research, development and deployment with degrees of 
knowledge and can include multiple EPC projects (possibly at different levels). Deliverable maturity examines to what degree a defined engineering deliverable is achieved ("completeness of engineering deliverables" $\left.{ }^{64}\right)$. It concentrates on the data quality with respect to the tasks required for one TRL; for example, the quality of measured values of single indicators. A deliverable is seen as mature if it fulfills certain quality requirements concerning purpose, context and documentation ${ }^{64}$. Both concepts, deliverable maturity and technology maturity, share increasing similarities towards higher TRLs (deployment, i.e. when a proposed deliverable and the TRL indicator for a mature technology overlap) or if the EPC project contains (research and) development activities as part of its engineering.

\section{A TRL scale specific for the chemical industry}

\subsection{TRLs and innovation phases}

The following TRL titles are suggested for the chemical industry: Idea, Concept, Proof of concept, Preliminary process development, Detailed process development, Pilot trials, Demonstration and full-scale engineering, Commissioning, and Production. These nine TRLs can now be linked to the definitions of broader (innovation) phases that a technology passes through (see section 2.1) in the following way: Basic research is conducted before the TRL scale begins. Applied research is then conducted from TRL 1 up to TRL 4. There is no clear line that separates research and development in terms of TRLs, as knowledge of both categories is needed in order to advance technological maturity in preliminary process development. While only rough process concepts are at hand at TRL 3, systematic development starts with TRL 4. TRL 5 and 6 are seen as main development stages. TRL 7 includes development achievements as well as the engineering and design of the full-scale plant which as detailed preparation and planning of implementation is characteristic for deployment. In the deployment stages TRL 8 and 9, the 
technology is actively brought into effect in the economic environment. However, during plant commissioning, especially start-up, final development activities (e.g. minor adaptions if a built solution turns out to be impractical) have to be carried out that lead to substantial advances in knowledge. For this reason, TRL 8 also holds characteristics of a development phase. The progression and overlap of the described phases is shown in Figure 3. A similar understanding was presented by Cornford \& Sarsfield ${ }^{21}$ who see 'physics' (TRLs 1-3), 'engineering' (TRLs 37) and 'production'(TRLs 7-9) as phases of a 'technology development cycle'21. Only recently, another similar understanding was presented by Humbird ${ }^{24}$ who describes the phases 'fundamental R\&D' (TRLs 1-3), 'scale-up and integration' (TRLs 4-6) and 'demonstration and commercial deployment' (TRLs 7-9).

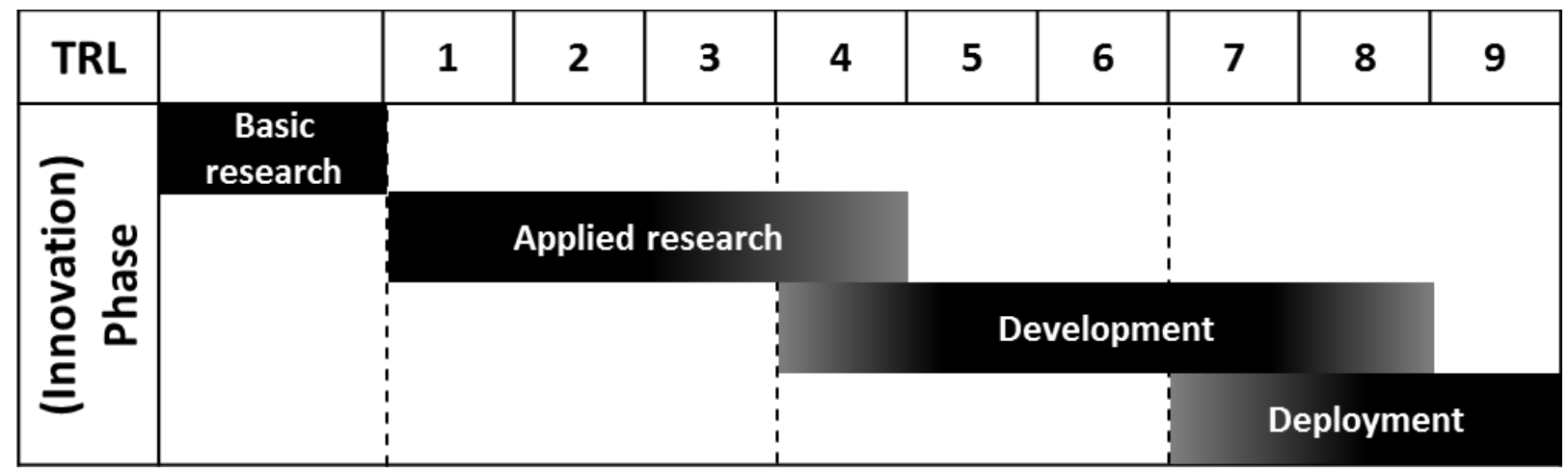

Figure 3: TRLs attributed to (innovation) phases 'basic research', 'applied research', 'development' and 'deployment' 


\subsection{Criteria - aspects of chemical RD\&D}

\subsubsection{Qualitative criteria}

Criteria for TRL rating can be qualitative or quantitative. Qualitative criteria present nominal indicators whose states can be directly judged (e.g. knowledge of reaction conditions, examples of carried out activities, description). Quantitative criteria contain indicators that are expressible in numeric values of underlying progressing scales (e.g. capacity, time, or cost). In Table 2, these indicators are translated into inequalities in order to allow them to be judged as true or false.

Title and Description. In all scales, TRLs are given a title that is supposed to give an overview and first impression of the respective level as well as to facilitate communication of TRLs. In addition to titles, short descriptions are given in all TRL scales. Descriptions further explain the TRLs, their main activities completed within them and their achievements. This work incorporates wordings that practitioners often use when communicating projects.

General project aspects. General project aspects are presented in Table 2, which subsumes criteria that characterize an RD\&D project's stage. The existence of concrete, tangible work results often serves as a way of checking project progress. In addition to the tangible work results, the workplace gives an indication of the project progress and technology maturity. In the chemical industry, typical steps in technology maturity are characterized by types of plants used. With advancing process development, the specifications of the chemical product are refined. At the same time, the features that make selling the chemical product possible are detailed in interrelation with the market's needs. These features define the product in its economic sense ${ }^{53}-$ criterion: product (economic). This criterion concentrates on the technical properties of a product and the activities usually carried out in order to define them. 
Engineering aspects. When engineering a new chemical technology, $R \& D$ of the chemical conversion of material and related equipment, called '(chemical) reaction engineering', is often separated from $\mathrm{R} \& \mathrm{D}$ of the physical effects occurring in chemical plants (e.g. state, form, composition of material), called '(chemical) process engineering'. The reaction engineering aspect mainly includes knowledge about the reaction pathway or network as well as its thermodynamic characteristics and kinetic behavior. It additionally includes information needed in order to design the equipment in which the chemical conversion is carried out. The process engineering aspect mainly includes the identification and detailing of unit operations, all associated material properties and descriptions of physical behavior, energy flows and carriers as well as associated equipment design. Process engineering deals with both the RD\&D of single process units and small-scale effects as well as the composition of the complete plant. The structure and function of a process or plant is depicted in flow diagrams or process schemes; they play an important role in the engineers' communication about a technology. As their levels of detail clearly show graduations in knowledge about a technology, flow diagrams are added as a distinct criterion.

\subsubsection{Quantitative criteria}

Capacity / Scaling factors. Most notably, a plant's capacity (or throughput or size) is a quantitative criterion for TRL rating in the chemical industry. It allows for a quick comparison of a current research and development plant to a reference full-scale plant. The reference full-scale plant's capacity can for example be derived from existing plants that are typical for similar technologies or from a projected plant whose capacity is based on market analysis (demandbased). 
The increase in production capacity during RD\&D varies considerably with different types of technologies. Therefore, distinguishing between types of technologies becomes necessary (similarly ${ }^{12}$ ). We assume that a chemical technology is distinctly represented by a chemical process. In the chemical industry, similar products are typically produced in similar process types (e.g. base chemicals in large, continuously operated plants or pharmaceuticals in smaller, batch-wise operated plants). We conclude that distinguishing product groups is an appropriate way of distinguishing types of chemical technologies with similar capacity increases during RD\&D. The distinction of product groups by degree of differentiation and production capacity into true commodities, pseudo commodities, fine chemicals, and specialty chemicals as introduced by Kline ${ }^{65}$ is used in the presented TRL scale. Although TRLs are more characterized by a level of information than a tangible object's size, both aspects are connected in chemical development as it is often required to build a bigger plant in order to answer a set of more indepth questions (which will be associated with the next level of readiness). Exponential growth as a model for increasing plant size during development is described in literature ${ }^{19,24,32}$. This growth principle was confirmed in expert interviews to be suitable to adopt for TRL indication. The bases for the exponential functions are equivalent to the scale-up factor from one TRL to the next. Typical scale-up factors for the different process types were retrieved from subject-matter expert interviews and compared to literature ${ }^{19,24,32,66}$. Due to the low quantity of data and lack of consistent opinions, the selected values do not result from regression analysis but reflect the authors' best judgement: 7 for true commodities, 6 for pseudo commodities, 4 for fine chemicals, 3 for specialty chemicals.

TRLs are ranks that allow a comparison as being lower, higher, or equal but do not comprise meaningful rank differences and is thus an ordinal concept; however, for this criterion only, it is 
treated as cardinal as TRL numbers have shown to be adequate reference points. General efforts for transforming the ordinal scale into a cardinal scale were made ${ }^{61}$ but remain inconclusive as they are based on experts' opinions about the (cardinal) magnitude of differences between TRLs; the underlying scale for those differences being 'maturity' or 'readiness'. No meanings of this scale or values in it are reported. In our understanding, it is necessary to include descriptive, qualitative criteria in the distinction of levels of knowledge. It is thus impossible to transform TRLs in general into cardinal values.

In Table 2, the capacities are given as percentages of the reference full-scale plant capacity and their inverses depict the scale-up factor from the current level to a reference full-scale plant (values rounded and adapted according to expert feedback). Values for ideation and concept phase are not given due to absence of actual product formation. Similarly, numbers for TRL 8 which is seen as initiated commissioning of a full-scale plant - are omitted since knowledge gains at this level do not come along with capacity increase.

Despite working for a range of example technologies, this criterion has to be treated with great caution and only gives rough indications about technology readiness as it was set up for average technology developments using rules of thumb; actual capacity development may differ for various reasons, for example the use of multi-purpose and thus non technology-specific pilot plants.

\subsection{Indicators - details of chemical RD\&D}

Detailed indicators that reflect the states of the selected criteria are presented in Table 2. These indicators represent the levels of knowledge gained about a chemical technology in the respective aspect. The levels speak for the readiness of a technology for the selected criterion 'economically sustainable production in business-relevant operation'. 
Table 2: TRLs in the chemical industry, specific and detailed criteria and indicators (revised and extended from ${ }^{20}$, see also ${ }^{25}$ )

\begin{tabular}{|c|c|c|c|c|c|c|c|c|c|c|}
\hline & TRL & 1 & 2 & 3 & 4 & 5 & 6 & 7 & 8 & 急 \\
\hline & Title & Idea & Concept & Proof of concept & Preliminary process & Detailed process & Pilot trials & Demonstration and full- & Commissioning & Production \\
\hline & Description & $\begin{array}{c}\text { Opportunities identified, } \\
\text { basic research translateded } \\
\text { into possible applications } \\
\text { (e.g. by brain-storming, } \\
\text { literature study) }\end{array}$ & $\begin{array}{l}\text { Technology concept and/or } \\
\text { application formulated, } \\
\text { patent research conducted }\end{array}$ & $\begin{array}{l}\text { Applied laboratory research } \\
\text { started, functional principle / } \\
\text { reaction (mechanism) } \\
\text { proven, predicted reaction } \\
\text { observed (qualitatively) }\end{array}$ & $\begin{array}{l}\text { Concept validated in } \\
\text { laboratory nenviroment, scale } \\
\text { up preparation stated, short- } \\
\text { cut procecess modeles found }\end{array}$ & \begin{tabular}{|c|} 
Process models found, \\
property data analysed, \\
simulation of process and \\
pilot plant uning bench scale \\
information
\end{tabular} & \begin{tabular}{|c|} 
Pilot plant constructed and \\
operated with how rate \\
production products \\
approved in frana applicicition, \\
detailed processs models \\
found
\end{tabular} & $\begin{array}{l}\text { Parameter and performance } \\
\text { of pilit plant toptimized, } \\
\text { (optional) demo plant } \\
\text { constructeded and operatating, } \\
\text { equipment specification } \\
\text { including components that } \\
\text { are type conferrable to full- } \\
\text { scale production }\end{array}$ & $\begin{array}{l}\text { Products and processes } \\
\text { integrated in organisational } \\
\text { structure (hardware and } \\
\text { software, futu-fccale plant } \\
\text { constructed }\end{array}$ & $\begin{array}{l}\text { Full-scale plant audited (site } \\
\text { acceptance test), turn-key } \\
\text { plant, production operated } \\
\text { over the full range of } \\
\text { expected conditions in } \\
\text { industrial scale and } \\
\text { environment, performance } \\
\text { guarantee enforceable }\end{array}$ \\
\hline & Tangible work result & $\begin{array}{l}\text { idea / rough concept / / ision/ } \\
\text { strategy paper }\end{array}$ & $\begin{array}{l}\text { Technology concept } \\
\text { formulated, list of solutions, } \\
\text { future R\&D activities planned }\end{array}$ & $\begin{array}{l}\text { Proof of concept (in } \\
\text { laboratory) }\end{array}$ & $\begin{array}{l}\text { Documentation of } \\
\text { reproduced and predictable } \\
\text { (quantitative) experiment } \\
\text { results, multiple atherative } \\
\text { procosss concepts evaluated }\end{array}$ & \begin{tabular}{|} 
Parameter and property \\
data, few atternative process \\
concepts evaluated in detail
\end{tabular} & Working pilot plant & $\begin{array}{l}\text { Optimized pilot plant, } \\
\text { (optional) working demo } \\
\text { plant, sample production, } \\
\text { finalized and ualified } \\
\text { system and buildini plan }\end{array}$ & $\begin{array}{l}\text { Finalized and qualified } \\
\text { system and building plan }\end{array}$ & $\begin{array}{l}\text { Full-scale plant tested and } \\
\text { working }\end{array}$ \\
\hline $\begin{array}{l}\text { General } \\
\text { project } \\
\text { criteria }\end{array}$ & Workplace & $\begin{array}{l}\text { Office (sheets of paper } \\
\text { (physical or digital), } \\
\text { whiteboard or similar) }\end{array}$ & $\begin{array}{l}\text { Office (sheets of paper } \\
\text { (physical or digital), } \\
\text { whiteboard or similar) }\end{array}$ & Laboratory & Laboratory & Laboratory/miniplant & Pilot plant, technical center & $\begin{array}{l}\text { Pilot plant, technical centre, } \\
\text { (optional) demo plant } \\
\text { (potentially incorporated in } \\
\text { production site) }\end{array}$ & Production site & Production site \\
\hline & Product (economic) & $\begin{array}{l}\text { General research (intermal or } \\
\text { external), that can influence } \\
\text { the product concept, user } \\
\text { survey conducted }\end{array}$ & $\begin{array}{l}\text { Initial product concept } \\
\text { formulated, detailed user } \\
\text { survey conducted }\end{array}$ & $\begin{array}{l}\text { Product concept and } \\
\text { resulting applications tested } \\
\text { in laboratory, first user tests } \\
\text { conducted }\end{array}$ & $\begin{array}{l}\text { Further experiments } \\
\text { conducted to broaden } \\
\text { application spectrum / } \\
\text { improve usability, user } \\
\text { feedback process } \\
\text { implemented }\end{array}$ & \begin{tabular}{|l|} 
Product properties detailed \\
\end{tabular} & $\begin{array}{l}\text { Product properties finalized } \\
\text { (will not be changed) }\end{array}$ & $\begin{array}{l}\text { Tested in inculustriflly relevant } \\
\text { working environment }\end{array}$ & $\begin{array}{l}\text { Final product customer } \\
\text { accepted and final feedback } \\
\text { included }\end{array}$ & $\begin{array}{l}\text { Product ready } \\
\text { (for sale) }\end{array}$ \\
\hline & $\begin{array}{l}\text { Reaction engineering } \\
\text { (including kinetics, } \\
\text { thermodynamics, } \\
\text { property data, } \\
\text { conversion, selectivity, } \\
\text { yield) }\end{array}$ & $\begin{array}{c}\text { Product group/class, } \\
\text { technology fifld specified } \\
\text { (e.g. fuels, minerals, } \\
\text { technical gases, } \\
\text { biotechnology, catalyst } \\
\text { change, nanotechnology) }\end{array}$ & $\begin{array}{l}\text { Chemical reaction selected, } \\
\text { number of reaction steps } \\
\text { identified }\end{array}$ & $\begin{array}{l}\text { Target values defined (e.g. } \\
\text { for conversion, selectivity, } \\
\text { yield) for laboratory scale, } \\
\text { information about mass } \\
\text { transfer (reilevant parameters } \\
\text { observed), therrmodynamics, } \\
\text { kinetic description of main } \\
\text { reaction, physical properties } \\
\text { and catalasystsynthesis } \\
\text { obtained, mass balance } \\
\text { closed }\end{array}$ & \begin{tabular}{c|} 
Feasibility of reaction \\
confirmed, reaction \\
optitimized in alaboratory scale \\
with respect to conversion, \\
selectivity, additives, \\
catallysts, solvents, and side- \\
products
\end{tabular} & 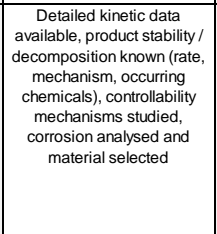 & $\begin{array}{c}\text { Product and reaction (fully) } \\
\text { discovered and understood, } \\
\text { kinetic system of all cocurring } \\
\text { reactions }\end{array}$ & 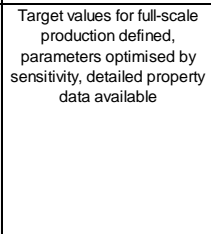 & Startup of plant initiated & $\begin{array}{l}\text { Target values for full-scale } \\
\text { plant met, optimisation }\end{array}$ \\
\hline 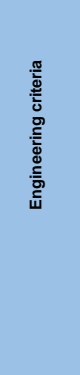 & \begin{tabular}{|c} 
Process engineering \\
(including up- $\&$ \\
downstream and process \\
technology of reaction \\
steps)
\end{tabular} & & $\begin{array}{l}\text { Unit operations (classes) } \\
\text { identified (e.g. separation) }\end{array}$ & $\begin{array}{l}\text { Options for unit operations } \\
\text { found (e.g. distillation), } \\
\text { single steps/unit operation } \\
\text { options conducted }\end{array}$ & 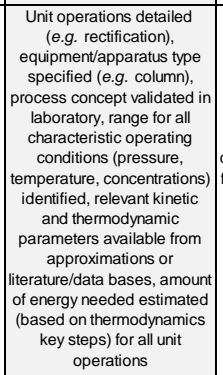 & 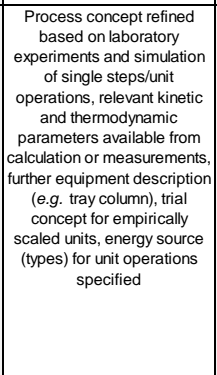 & 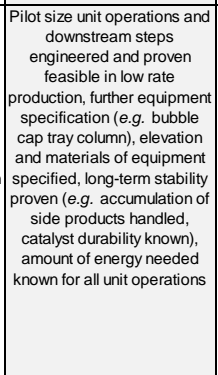 & 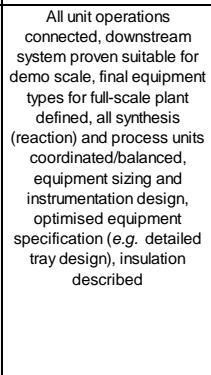 & $\begin{array}{l}\text { Equipmentapparatuses } \\
\text { adapted to tull-scale processs }\end{array}$ & Optimisation \\
\hline & Flow diagrams & - & & $\begin{array}{l}\text { Block diagram, crude/initial } \\
\text { concepts tor processess } \\
\text { identified }\end{array}$ & $\begin{array}{l}\text { Enhanced block diagram, } \\
\text { including mass flows }\end{array}$ & $\begin{array}{l}\text { Process flow diagram } \\
\text { developed including mass } \\
\text { and energy fllows }\end{array}$ & $\begin{array}{c}\text { Enhanced process flow } \\
\text { diagram, essential } \\
\text { instruments (e.g. valves) } \\
\text { decided (energy, mass } \\
\text { flows), process integration } \\
\text { concept }\end{array}$ & $\begin{array}{l}\text { P\&ID diagram developed (all } \\
\text { recycling streams/circular } \\
\text { flows, list of all engines) }\end{array}$ & Optimisation & \\
\hline $\begin{array}{l}\text { Capacity as } \\
\text { traction of }\end{array}$ & $\begin{array}{l}\text { True commodities } \\
\text { Pseudo commodities }\end{array}$ & - & - & $\frac{50,001 \% / \geq 100000}{<0030}$ & $\frac{\leq 0,01 \% / \geq 10000}{500 \% 0 / 15000}$ & $\frac{\leq 0,1 \% / \geq 1000}{\leq 1 \% />100}$ & $\frac{51 \% / 2100}{51 \% />100}$ & $\frac{\leq 3 \% / 233}{50 />33}$ & - & $100 \%$ \\
\hline & $\begin{array}{l}\text { Psudo commoditie } \\
\text { Fine chemicals }\end{array}$ & & & $\begin{array}{l}0 \leq, 003 \% \% / 233333 \\
\leq 0,025 \% / \geq 4000\end{array}$ & $\begin{array}{l}\leq, 0,0 \% / 25000 \\
\leq 0,1 \% / \geq 1000\end{array}$ & $\begin{array}{l}\leq 0,1 \% / \geq 1000 \\
\leq 0,4 \% / \geq 250\end{array}$ & $\begin{array}{l}\leq 1 \% / \geq 100 \\
\leq 2 \% / \geq 50\end{array}$ & $\begin{array}{l}3 . \% / \geq 33 \\
\leq 7 \% / \geq 15\end{array}$ & & $\frac{100 \%}{100 \%}$ \\
\hline & Specialty chemicals & & & $\leq 0,125 \% / \geq 800$ & $\leq 0,4 \% / \geq 250$ & $\leq 1 \% / \geq 100$ & $\leq 4 \% / \geq 25$ & $\leq 10 \% / \geq 10$ & & $100 \%$ \\
\hline
\end{tabular}




\section{Application of the revised scale}

\subsection{How to use the scale}

\subsubsection{Rating composed technologies}

The presented TRL scale is applicable to all chemical innovation projects that are directed at introducing a new technology to the market and thus can be considered to be in applied research, development or deployment stages.

TRLs can be assigned to technology elements at various tiers, from whole plants down to single pieces of equipment. The choice of the tier depends on the practitioner's motivation for using the TRL concept - which is usually a certain depth of analysis (literal sense: breakdown/dissolving into single components) of a technology. The technology should be fragmented into technology elements of the same logical level and TRLs should be given for each technology element. First concepts about analyzing an 'integration readiness' separate from the technology readiness and composing them into a 'system readiness' were presented in literature ${ }^{57}$ and may help a deeper understanding of the system. However, in our understanding, they are not needed in order to rate technology readiness as the information needed to integrate the element into a system is covered with TRLs as these describe the state of being ready for a targeted application in a system (see also ${ }^{15}$ ). One single number for a composed technology can be desired by some practitioners. This desire can be dealt with in several ways:

a. It can be argued that a single number should not be given.

b. An average number can be presented. (TRLs are an ordinal scale; possible averages are median or mode.)

c. The maximum value of the system elements' TRLs can be chosen as representative value. 
d. The minimum value of the system elements' TRLs can be chosen as representative value (critical technology element, 'weakest link in the chain').

We strongly recommend reporting all TRLs rated along with the single technology elements in order not to lose information and additionally presenting the minimum number as the overall TRL (d.) in order to identify and communicate critical pathways which can indicate the effort that has to be put into RD\&D to result in a mature technology. Giving a single, higher number annihilates the transparency gained by the comprehensible rating of the technology elements and can lead to expectations that cannot be fulfilled (e.g. in subsequent TEA, forcing unreasonable technical assumptions for a technology element that is less developed).

\subsubsection{Rating technology elements}

When rating the TRL of a given technology element, it is suggested to go through the table of criteria and indicators (see Table 2) in a methodological way. The suggested nine-step approach is shown in Figure 4. 


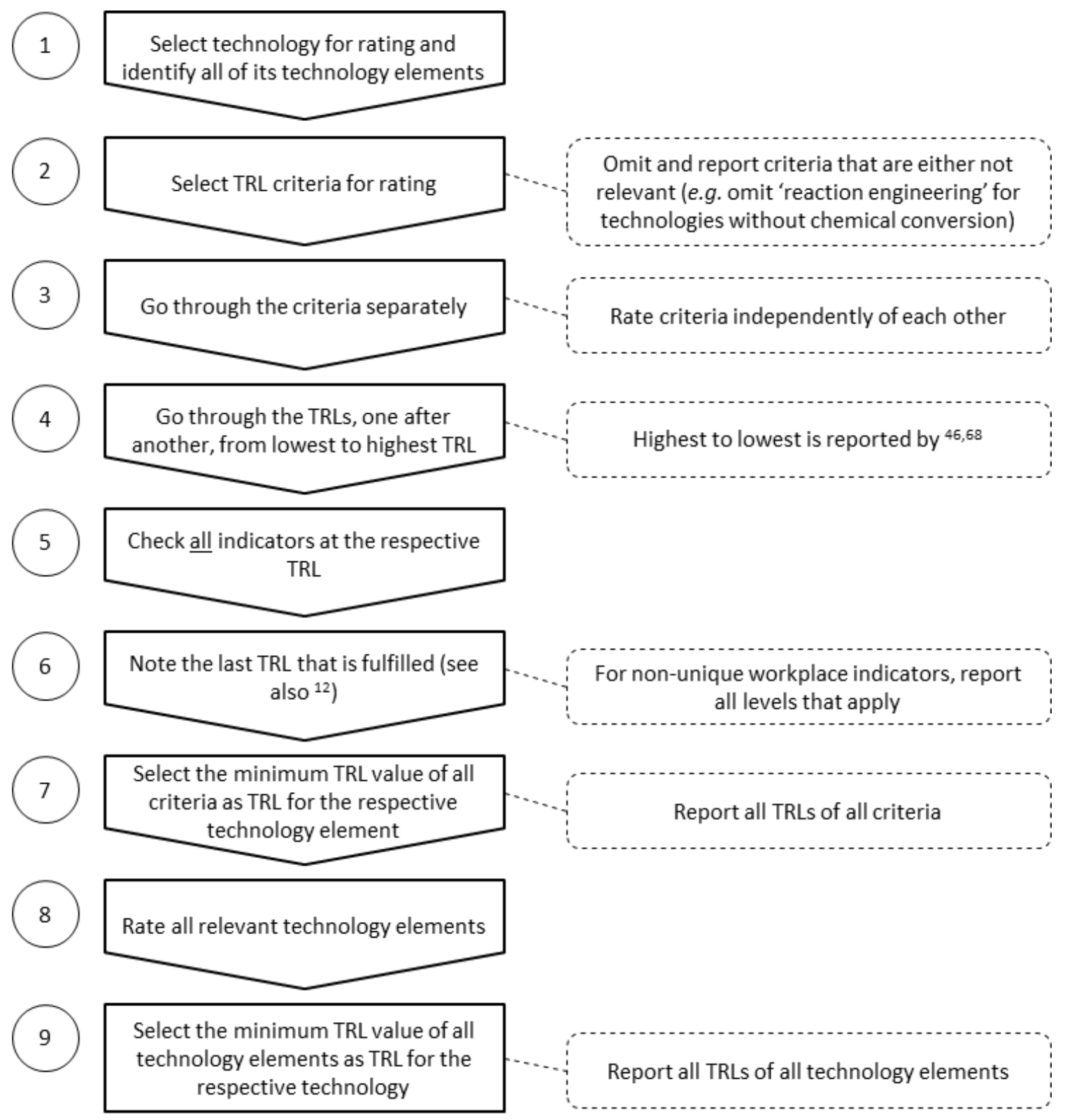

Figure 4: Stepwise approach for TRL rating of technology elements (steps 1-7) and composed technologies (steps 8-9)

Modifications to existing technologies result in new technologies. Modifications can thus be treated like overall new technologies and have to pass the same RD\&D steps, from a first 
modification idea to a running modified system. However, as major aspects of the technology may already contain characteristics of later TRLs, technology modifications may more quickly pass earlier TRLs. Vice versa, if a technology turns out to not be able to meet the requirements for the next TRL; the R\&D falls back and the TRL rating is set back to an earlier level.

\subsubsection{Data accessibility}

Ideally, the collected data reflect the state of the current RD\&D. However, there are a variety of reasons why the accessible data for TRL rating fall behind the actual development, depending on stakeholder perspectives (2.5). In particular, confidentiality is a frequently encountered challenge in data collection ${ }^{17}$. For external stakeholders, it can be advised to distinguish between the 'real TRL' that describes the technology as in its factual existence on the one hand and the 'observed TRL' that describes a technology with the data that are accessible to the practitioner performing the analysis and rating on the other hand. While most will intrinsically desire the 'real TRL', rating the available data can itself be an important step when for example preparing data availability-based technology assessment: For the evaluation of single projects by internal stakeholders, the 'observed TRL' is often favored. If a broader perspective is taken, for example by external stakeholders evaluating emerging technology fields or value-chains, the 'real TRL' is recommended.

Other frequently encountered challenges are: Information needed to rate TRLs is commonly spread across multiple people and can therefore be time-consuming, especially in later TRLs which usually contain larger project teams. In addition, TRL ratings always hold the potential for conflicts as it may for example disclose that a development project is not as advanced as it was planned to be. 


\section{Follow-along example: TRL rating of a multiphase hydroformylation process}

The stepwise TRL rating approach (see Figure 4) is exemplified in a brief manner in the following paragraphs (for a more detailed explanation see ${ }^{25}$ ):

Step 1 - Technology selection: The selected technology is a process for the continuous hydroformylation of long-chain alkenes, which is currently researched in a mini plant at Technische Universität Berlin, Germany ${ }^{67-69}$. The targeted innovation is the application of surfactant-based microemulsion systems as reaction media. For a first TRL rating, it is decided to view the complete plant as one single technology element. For a single technology element, steps $8 \& 9$ are not applicable.

Step 2-Criteria selection: All criteria are applicable.

Steps 3-6 - Criteria TRL rating: TRLs 1-3 are excluded from the following discussion as all respective indicators of each criterion were quickly confirmed by the development team.

The combined criterion 'Title and description' indicates TRL 4. The status of the development project is described as a process concept that is validated in the laboratory environment. After comparison of process alternatives, the scale-up preparation was started with construction of a mini plant. Short-cut process models are found but there is no complete process simulation. In the mini plant not all process steps are connected in a single operation or have not been conducted yet. It becomes evident that the description's indicators of TRL 5 cannot be positively answered.

The criterion 'tangible work result' indicates TRL 4. It is provided by a documentation of reproduced and predictable experiment results which is shown for process alternatives. A detailed evaluation of multiple alternatives as demanded for TRL 5 is not claimed. 
The criterion 'workplace' indicates TRL 6 . The workplace is in a university mini plant facility in a small technical center.

The criterion 'product (economic)' indicates TRL 4. It is analyzed as follows: The process currently employs a model substrate but ideas for the product utilization exist. Chemical properties of the product are known. So far potential market opportunities could not be translated into detailed product requirements (e.g. purity).

The criterion 'reaction engineering' indicates TRL 4. The technical feasibility of the reaction concept was confirmed and optimized in laboratory scale. The reactions controllability was researched and the material selection for the plant followed detailed corrosion analysis. However, a complete, quantitative model description of the reaction system's kinetic behavior is not at hand, which excludes TRL 5.

The criterion 'process engineering' indicates TRL 4. Options for all unit operations were detailed and the respective equipment was selected and specified. For a range of operating conditions, their impacts on thermodynamic properties and on kinetic behavior of the system is described, using a combination of detailed measurements and approximations from literature data. A preliminary energy demand estimate was performed. TRL 5 is excluded as in-depth equipment descriptions with detailed energy balances are not available for all process steps.

The criterion 'flow diagrams' indicates TRL 5. A first process flow diagram for a fullscale plant concept was designed. Assumptions made indicate that the reaction and separation are not understood in all detail. There are only first heat integration ideas.

The criterion 'scale' indicates TRL 4. The theoretical product capacity of the mini plant lies between 100 and $500 \mathrm{~kg} / \mathrm{a}$. This range is seen as more than $0.001 \%$ but less than $0.01 \%$ of a full-scale plant's capacity for this commodity. 
Step 7 - Overall TRL rating: The criterion 'workplace' is assigned TRL 6, the criterion 'flow diagrams' is assigned TRL 5, all other criteria are assigned TRL 4. Following the weakest link in the chain' logic, the technology is rated to be TRL 4 .

\subsection{Tasks following TRL rating}

\subsubsection{Data availability-based assessment}

Selecting adequate technology assessment methods is difficult: Overly complex and timeconsuming methods often lead to forcing assumptions that narrow the path for future development, while too simple methods that do not consider all known relevant data lead to lack of information. Methods in all assessment fields depend on the availability of data which is closely linked to development progress. The need of different methodologies sorted by data availability is addressed for example for general $\mathrm{TEA}^{47}$, in capital cost estimation frameworks from plant engineering ${ }^{63,70,71}$ or uncertainty evaluation in life cycle assessment studies ${ }^{72}$. As TRLs depict development progress, the TRL scale presents a suitable framework for the selection of adequate assessment methods. TRL-based assessment frameworks were recently presented $^{17,20,25,26}$ and follow a two-step approach: Firstly, evaluating data availability by TRL rating and secondly, selecting TEA methodology that fits the available data from tables which sort methods or indicators by TRL according to their data input requirements.

\subsubsection{Basis for technology development planning}

An important point of discussion is if and how a technology maturation plan in the chemical industry can be derived from TRLs. After rating technology maturity, the US DoE advises the creation of a technology maturation plan ${ }^{8}$ containing activities and specific requirements that are needed in order to complete development and to "progress a technology from one TRL to the next" ${ }^{\prime 2}$. Cornford and Sarsfield state that the "current TRL schema $[\ldots]$ is inadequate for detailed 
project planning" 21 which leads them to introducing a tool solely based on measurable physical performance. This tool can however only be set up for individual technology innovations and the selection of the physical properties (criteria) and the numeric distances between the levels remains subjective. It is believed that the detailed understanding of the readiness incorporating specific technical indicators as presented above can assist with deriving technical development plans. The elaboration of detailed approaches is left to future research.

\section{Critical review and outlook}

TRL scales were invented for rating the maturity of space exploration technologies which combine elements of different technology fields ${ }^{2}$. For this reason, the initial scales are rather vague and general, leading to the advantage of allowing for the evaluation of projects from different disciplines with the same principles. However, a trade-off between comparability of technologies of different fields on the one hand and more comprehensible rating of technologies from a single field on the other hand was identified. In the chemical industry, there is a need for an adapted and more specific TRL scale that helps stakeholders throughout academia, industry and policy-making to evaluate and communicate RD\&D progress and associated risk, to derive managerial tasks such as setting up technology portfolios, or to assess a technology with the most accurate methods possible ${ }^{17,20}$.

To answer the identified need, this paper provides the first comprehensive TRL understanding tailored to the chemical industry. For this, it was first necessary to discuss the general nature of TRL scales and methods for differentiating TRLs - a fundament that is largely missing from the past scientific discourse on TRLs. Three main issues were discussed: a) Beginning and end of the scale have to be set up according to a selected criterion since there is no objective understanding for technological progress. b) TRLs are seen as milestones rather than phases. c) In order to 
achieve a TRL, it is in principle required to prove the existence of knowledge and data by tangible implementation of the technology at the current RD\&D state. This may be omitted after expert judgement for highly standardized unit operations.

In addition, the adaption of the TRL concept to the chemical industry requires the introduction of concepts specific to chemical RD\&D and the inclusion of the perspectives of all stakeholders involved in it. For the latter purpose, an economic criterion was found to be the most suitable for rating a technology's maturity: TRL rating begins with ideas of how basic research can be exploited in a technology for commercial use (TRL 1) and ends with an implemented technology that is economically sustainable in business-relevant operation (TRL 9).

The lack of specification was then tackled by combination, detailing and explanation of current (popular) scales, abstraction of best practices in engineering for process development as well as expert interviews and verification in first application of the developed scale (e.g. in ${ }^{25}$ ). This paper notices that for a comprehensive understanding of maturity of chemical innovations and facilitating the specification of TRLs, a technology is best divided into its different aspects that need to advance in order to yield overall technology maturation. Therefore, in addition to adapted titles and descriptions, further criteria were selected and introduced to extend the scale: tangible work result, workplace, product (economic), reaction engineering, process engineering, flow diagrams, capacity / scale-up factor. These criteria were filled with detailed indicators that allow for a more comprehensible TRL rating (see Table 2). Suggested TRLs for the chemical industry are: Idea, Concept, Proof of concept, Preliminary process development, Detailed process development, Pilot trials, Demonstration and full-scale engineering, Commissioning, and Production. 
There are inherent limitations to the meaning of the developed scale: First, although the applied methodology is believed to lead towards a more objective understanding of TRLs and more comprehensible ratings, exact reproducibility cannot be claimed, thus still leading to a certain degree of subjectivity in the presented the scale and ratings based on it. Second, indicators give as their name suggests - hints or clues about the readiness as they stand for the state of an associated criterion. At the same time, this means that indicators cannot definitely imply a certain readiness. In addition, the presented sets of indicators do not offer complete descriptions of a technology. TRLs present an ordinal scale. As for example shown for the capacity / scale-up factor, a cardinal understanding can be assumed with respect to quantitative criteria only; however, values depend on the selected metrics and thus remain subjective. Deviations in the actual development's capacities may appear due to strategic reasons (e.g. use of existing plants, portfolio-driven decisions). As pointed out in this paper, it is not recommended to rely on just one criterion (e.g. capacity) for TRL rating. A strong conclusion can only be drawn from the evaluation of a set of criteria.

This paper aims to further strengthen the discussion about TRLs in the chemical industry and to encourage application and adaptions of the presented scale. Future work can for example contain: Additional criteria (e.g. safety engineering, process automation), more project characteristics (e.g. involved people and institutions), and guidance on how to derive a maturation plan with RD\&D tasks, or the adaption of the scale to different purposes (e.g. readiness for ecologically sustainable production). A step-by-step approach for TRL rating was presented. The practitioner's influences might be further mitigated by compiling and arranging indicators in a tool that for example asks questions to its operator about the technology and guides through the TRL rating (e.g. see ${ }^{73,74}$ ). 


\section{Author information}

Corresponding author

* To whom correspondence should be addressed. Phone: +49-(0)-30-314-24973. E-mail: schomaecker@tu-berlin.de 


\section{Funding}

Authors 1 and 3 received funding from the European Institute of Innovation and Technology

Climate-KIC. Author 1 received funding from the German Federal Ministry of Education and Research (BMBF). 


\section{Acknowledgement}

The authors would like to thank Matthias Kraume, Michael Schwarze, Erik Esche (TU Berlin), Jochen Norwig (Covestro), Alexis Bazzanella (DECHEMA), Michael Carus, Achim Raschka (NOVA Institute), Magnus Fröhling (TU Bergakademie Freiberg, now TU Munich), Annemarie Falke (TU Bergakademie Freiberg), Annika Marxen (IASS Potsdam, now TU Berlin) and Norbert Kockmann (TU Dortmund) for fruitful discussions and valuable leads as well as Jason Collis (TU Berlin) for proofreading. This work was funded by the European Institute of Technology (EIT), a body of the European Union, via Climate-KIC and its flagship program 'enCO2re' and the German Federal Ministry of Education and Research (BMBF) FONA3 r+Impuls program. 


\section{Supporting information}

S1: Table S1 "Compilation of popular TRL scales with titles and further descriptions" 


\section{Nomenclature}

CBiRC

Center for Biorenewable Chemicals

CRL

Cost Readiness Level

EARTO

European Association of Research and Technology Organisations

EPC

Engineering, Procurement, Construction

ESA

European Space Agency

H2020

Horizon 2020

IRL

Integration Readiness Level

IRL

Investment Readiness Level

ISO

International Organization for Standardization

MRL

Manufacturing Readiness Level

NASA

National Aeronautics and Space Administration

$R \& D$

Research and Development

RD\&D

Research, Development and Deployment

RRL

Reuse Readiness Level

SRL

System Readiness Level

TEA

Techno-Economic Assessment

TRL

Technology Readiness Level

US DoD

United States Department of Defense

US DoE

United States Department of Energy

US HHS

United States Department of Health and Human Services 


\section{References}

(1) Miremadi, M.; Musso, C.; Oxgaard, J. Chemical Innovation: An Investment for the Ages. McKinsey Chem. 2013, 1-9.

(2) Mankins, J. C. Technology Readiness Levels, A White Paper (1995, Edt. 2004); Advanced Concepts Office, Office of Space Access and Technology, NASA, 2004.

(3) Klar, D.; Frishammar, J.; Roman, V.; Hallberg, D. A Technology Readiness Level Scale for Iron and Steel Industries. Ironmak. Steelmak. 2016, 43 https://doi.org/10.1080/03019233.2015.1109024.

(4) European Association of Research and Technology Organizations (EARTO). The TRL Scale as a Research \& Innovation Policy Tool, EARTO Recommendations; 2014.

(5) Banke, J. Technology Readiness Levels Demystified, National Aeronautics and Space Administration (NASA) https:/www.nasa.gov/topics/aeronautics/features/trl_demystified.html (accessed Aug 16, 2018).

(6) US National Aeronautics and Space Administration (NASA). NASA's Technology Readiness Levels https://esto.nasa.gov/files/trl_definitions.pdf (accessed Aug 16, 2018).

(7) US National Aeronautics and Space Administration (NASA); Office of the Chief Engineer. NASA Procedural Requirements, Subject: NASA Systems Engineering Processes and Requirements (Updated w/Change 4), NPR 7123.1B -- AppendixE; 2013.

(8) US Department of Energy; Office of Management. Technology Readiness Assessment Guide, DOE G 413.3-4A; Washington, D.C., 2011. 
(9) US Department of Health and Human Services. Technology Readiness Levels (TRLs) for Medical Countermeasure Products (Drugs and Biologics) https://www.medicalcountermeasures.gov/federal-initiatives/guidance/integrated-trls.aspx (accessed Aug 16, 2018).

(10) NSF Engineering Research Center for Biorenewable Chemicals (CBiRC). Technology Readiness Levels https:/www.cbirc.iastate.edu/industry/technology-readiness-levels/ (accessed Aug 16, 2018).

(11) Bolat, S. Technology Readiness Level (TRL) put into practice https://serkanbolat.com/2016/02/17/technology-readiness-level-trl-put-into-practice/ (accessed Aug 30, 2018).

(12) Carmack, W. J.; Braase, L. A.; Wigeland, R. A.; Todosow, M. Technology Readiness Levels for Advanced Nuclear Fuels and Materials Development. Nucl. Eng. Des. 2017, 313, 177-184. https://doi.org/10.1016/j.nucengdes.2016.11.024.

(13) US Department of Defense; Assistant Secretary of Defense for Research and Engineering (ASD(R\&E)). Technology Readiness Assessment (TRA) Guidance; 2011.

(14) European Commission. EN HORIZON 2020 WORK PROGRAMME 2016 - 201720. General Annexes (European Commission Decision C (2017) 2468 of 24 April 2017), Annex G, Technology Readiness Levels (TRL); 2017.

(15) European Committee for Standardisation. ISO 16290:2013, Space Systems -- Definition of the Technology Readiness Levels (TRLs) and Their Criteria of Assessment; Brussels, 
2013.

(16) ESA TEC-SHS. Technology Readiness Levels Handbook for Space Applications, 1. Ed, 6th Rev., TEC-SHS/5551/MG/Ap; 2008.

(17) Zimmermann, A. W.; Wunderlich, J.; Buchner, G. A.; Müller, L.; Armstrong, K.; Michailos, S.; Marxen, A.; Naims, H.; Styring, P.; Schomäcker, R.; et al. TechnoEconomic Assessment \& Life Cycle Assessment Guidelines for CO2 Utilization; CO2Chem Media and Publishing Ltd, 2018. https://doi.org/10.3998/2027.42/145436.

(18) Ahn, E.-Y.; Kim, S.-Y.; Lee, J.-W. Technology Readiness Levels (TRLs) Indicator Development for Geoscience and Mineral Resources R\&D. Econ. Environ. Geol. 2015, 48 (5), 421-429.

(19) Zimmermann, A. W.; Schomäcker, R. Assessing Early-Stage CO2 Utilization Technologies-Comparing Apples and Oranges? Energy Technol. 2017, 5 (6), 850-860. https://doi.org/10.1002/ente.201600805.

(20) Buchner, G. A.; Zimmermann, A. W.; Hohgräve, A. E.; Schomäcker, R. TechnoEconomic Assessment Framework for the Chemical Industry - Based on Technology Readiness Levels. Ind. Eng. Chem. Res. 2018, 57, 8502-8517.

(21) Cornford, S. L.; Sarsfield, L. Quantitative Methods for Maturing and Infusing Advanced Spacecraft Technology. In IEEE Aerospace Conference Proceedings; 2004; pp 663-681.

(22) Merriam-Webster.com. Definition of prototype https://www.merriamwebster.com/dictionary/prototype (accessed May 5, 2018). 
(23) Oxford University Press. Definition of demonstration in English https://en.oxforddictionaries.com/definition/demonstration (accessed Aug 16, 2018).

(24) Humbird, D. Expanded Technology Readiness Level (TRL) Definitions for the Bioeconomy https://www.biofuelsdigest.com/bdigest/2018/10/01/expanded-technologyreadiness-level-trl-definitions-for-the-bioeconomy/ (accessed Nov 7, 2018).

(25) Buchner, G. A.; Wunderlich, J.; Schomäcker, R. (EST-2912) Technology Readiness Levels Guiding Cost Estimation in the Chemical Industry. In AACE International Transactions; Morgantown, WV, 2018; p EST.2912.1-23.

(26) Tsagkari, M.; Couturier, J.-L.; Kokossis, A.; Dubois, J.-L. Early-Stage Capital Cost Estimation of Biorefinery Processes: A Comparative Study of Heuristic Techniques. ChemSusChem 2016, 9, 2284-2297. https://doi.org/10.1002/cssc.201600309.

(27) Merriam-Webster.com. Definition of maturity https://www.merriamwebster.com/dictionary/maturity (accessed Aug 16, 2018).

(28) Merriam-Webster.com. Definition of mature https://www.merriamwebster.com/dictionary/mature\#h1 (accessed Aug 16, 2018).

(29) Merriam-Webster.com. Definition of readiness https://www.merriamwebster.com/dictionary/readiness (accessed Aug 16, 2018).

(30) Oxford University Press. Definition of technology in English https://en.oxforddictionaries.com/definition/technology (accessed Aug 16, 2018).

(31) Natural Resources Institute (NRET). UK DFID (R7468) NRETCodes of Practice; NRET 
Theme Papers on Codes of Practice in the Fresh Produce Sector; Chatham, Kent, 2007.

(32) Vogel, G. H. Process Development: From the Initial Idea to the Chemical Production Plan; Wiley VCH Verlag GmbH / Wiley-VCH: Weinheim, 2005.

(33) Wood-Black, F. Considerations for Scale-Up - Moving from the Bench to the Pilot Plant to Full Production. In Academia and Industrial Pilot Plant Operations and Safety; ACS Symposium Series Vol. 1163, Ed.; American Chemical Society: Washington, DC, 2014; pp 37-45. https://doi.org/10.1021/bk-2014-1163.ch003.

(34) Peters, M. S.; Timmerhaus, K. D.; West, R. E. Plant Design and Economics for Chemical Engineers, fith editi.; McGraw Hill: New York, 2004.

(35) Zlokarnik, M. Scale-up in Chemical Engineering, 2nd ed.; Wiley VCH: Weinheim, Graz, 2006.

(36) Behr, A.; Agar, D. W.; Jörissen, J. Einführung in Die Technische Chemie; Springer, Spektrum Akademischer Verlag: Heidelberg, 2010.

(37) IPCC Intergovernmental Panel on Climate Change; Climate Change 2007: Working Group III: Mitigation of Climate Change. Technology research, development, deployment, diffusion and transfer https://www.ipcc.ch/publications_and_data/ar4/wg3/en/tssts-ts-2-6-technologyresearch.html (accessed Oct 3, 2018).

(38) Avato, P.; Coony, J. Accelerating Clean Energy Technology Research, Development, and Deployment - Lessons from Non-Energy Sectors; World Bank Working Paper No. 138; 
The International Bank for Reconstruction and Development / The World Bank: Washington, D.C., 2008. https://doi.org/10.1596/978-0-8213-7481-8.

(39) National Science Foundation. What Is Basic Research? Annual Report 1953; 1953.

(40) American Chemical Society. Basic Research, Chemistry Carriers https://www.acs.org/content/acs/en/careers/college-to-career/chemistry-careers/basicresearch.html (accessed Feb 13, 2018).

(41) Oxford University Press. Definition of deployment in English https://en.oxforddictionaries.com/definition/deployment (accessed Feb 13, 2012).

(42) GridInnovation-on-line; GRID+ project; European Commission. Technology Readiness Level (TRL) http://www.gridinnovation-on-line.eu/articles/maturity/technology-readinesslevel-trl.kl (accessed Aug 16, 2018).

(43) Rybicka, J.; Tiwari, A.; Leeke, G. A. Technology Readiness Level Assessment of Composites Recycling Technologies. J. Clean. Prod. 2016, 112, 1001-1012. https://doi.org/10.1016/j.jclepro.2015.08.104.

(44) Nakamura, H.; Kajikawa, Y.; Suzuki, S. Multi-Level Perspectives with Technology Readiness Measures for Aviation Innovation. Sustain. Sci. 2013, 8 (1), 87-101. https://doi.org/10.1007/s11625-012-0187-z.

(45) Straub, J. In Search of Technology Readiness Level (TRL) 10. Aerosp. Sci. Technol. 2015, 46, 312-320. https://doi.org/10.1016/j.ast.2015.07.007.

(46) Greig, C.; Garnett, A.; Oesch, J.; Smart, S. Guidelines for Scoping and Estimating Early 
Mover Ccs Projects. Univ. Queensl., Brisbane 2014.

(47) van der Spek, M.; Ramirez, A.; Faaij, A. Challenges and Uncertainties of Ex Ante Techno-Economic Analysis of Low TRL CO2 Capture Technology: Lessons from a Case Study of an NGCC with Exhaust Gas Recycle and Electric Swing Adsorption. Appl. Energy 2017, 208, 920-934.

(48) Rubin, E. S. Evaluating the Cost of Emerging Technologies. Presentation to the Climit Workshop on Emerging CO2 Capture Technologies. Oslo Climit 2016.

(49) Rubin, E. S. Seven Simple Steps to Improve Cost Estimates for Advanced Carbon Capture Technologies. Present. to DOE Transform. carbon capture Technol. Work. Pittsburgh, PA, DOE NETL 2014.

(50) Brown, K. R.; McClesky, C. M. Paper Session II-B - National Spaceport Testbed. In 37th Space Congress Proceedings, Paper 16; Cocoa Beach, FL, 2000; pp 1-20.

(51) Rangan, V. K.; Shapiro, B. P.; Moriaty, R. T. Business Marketing Strategy: Cases, Concepts, and Applications; McGraw Hill / Irwin Series in Marketing: Burr Ridge, IL, 1995.

(52) Vitale, R. P.; Giglierano, J. J. Business to Business Marketing: Analysis and Practice in a Dynamic Environment; Cengage Learning: Mason, OH, 2002.

(53) Saavedra, C. A. The Marketing Challenge for Industrial Companies, Advanced Concepts and Practices; Springer International Publishing Switzerland, 2016.

(54) Hamaker, J. NASA Cost Estimating Initiatives, Meeting The Project Management 
Challenge, NASA HQ Cost Analysis Division, Presentation https://www.nasa.gov/pdf/293222main_62639main_1_pmchallenge_hamaker.pdf (accessed Aug 28, 2018).

(55)

US Department of Defense; OSD Manufacturing Technology Program; The Joint Service/Industry MRL Working Group. Manufacturing Readiness Level (MRL) Deskbook, Version 2.0; 2011.

(56) Blank, S. It's Time to Play Moneyball: The Investment Readiness Level https://steveblank.com/2013/11/25/its-time-to-play-moneyball-the-investment-readinesslevel/ (accessed Aug 28, 2018).

(57) Sauser, B.; Ramirez-Marquez, J.; Verma, D.; Gove, R. From TRL to SRL: The Concept of Systems Readiness Levels, Paper \#126. In Conference on Systems Engineering Research; Los Angeles, CA, 2006.

(58) Marshall (ed.), J.; Berrick, S.; Bertolli, A.; Bettenhausen, C.; Burrows, H.; Channan, S.; Delnore, V.; Downs, R. R.; Enloe, Y.; Falke, S.; et al. Reuse Readiness Levels (RRLs); 2010.

(59) Turton, R.; Bailie, R. C.; Whiting, W. B.; Shaeiwitz, J. A.; Bhattacharyya, D. Analysis, Synthesis, and Design of Chemical Processes; Prentice Hall, Pearson: Upper Saddle River, NJ, USA, 2012.

(60) Sinnott, R.; Towler, G. Chemical Engineering Design, 2014 repri.; Elsevier Ltd: Amsterdam, 2009. 
(61) Conrow, E. H. Estimating Technology Readiness Level Coefficients. J. Spacecr. Rockets 2011, 48 (1), 146-152. https://doi.org/10.2514/1.46753.

(62) European Commission. High-Level Expert Group on Key Enabling Technologies; Brussels, 2011.

(63) Dysert, L. R.; Christensen, P. AACE International Recommended Practice No. 18R-97; Cost Estimate Classificaton System - As Applied in Engineering, Procurement, and Construction for the Process Industries - TCM Framework: 7.3 - Cost Estimating and Budgeting; Morgantown, 2016.

(64) Stephenson, H. L.; Bredehoeft, P. R. (EST-2833) Maturity Assessment for Engineering Deliverables. In AACE International Transactions; Morgantown, WV, 2018; $\mathrm{p}$ EST.2833.1-24.

(65) Kline, C. H. Maximizing Profits in Chemicals. Chemtech 1976, 6 (2), 110-117.

(66) Pollak, P. Fine Chemicals: The Industry and the Business, 1st ed.; John Wiley \& Sons: Hoboken, NJ, 2007.

(67) Illner, M.; Müller, D.; Esche, E.; Pogrzeba, T.; Schmidt, M.; Schomäcker, R.; Wozny, G.; Repke, J. U. Hydroformylation in Microemulsions: Proof of Concept in a Miniplant. Ind. Eng. Chem. Res. 2016, 55 (31), 8616-8626. https://doi.org/10.1021/acs.iecr.6b00547.

(68) Pogrzeba, T.; Müller, D.; Hamerla, T.; Esche, E.; Paul, N.; Wozny, G.; Schomäcker, R. Rhodium-Catalyzed Hydroformylation of Long-Chain Olefins in Aqueous Multiphase Systems in a Continuously Operated Miniplant. Ind. Eng. Chem. Res. 2015, 54 (48), 
11953-11960. https://doi.org/10.1021/acs.iecr.5b01596.

(69) Pogrzeba, T.; Müller, D.; Illner, M.; Schmidt, M.; Kasaka, Y.; Weber, A.; Wozny, G.; Schomäcker, R.; Schwarze, M. Superior Catalyst Recycling in Surfactant Based Multiphase Systems - Quo Vadis Catalyst Complex? Chem. Eng. Process. Process Intensif. 2016, 99, 155-166. https://doi.org/10.1016/j.cep.2015.09.003.

(70) Cheali, P.; Gernaey, K. V.; Sin, G. Uncertainties in Early-Stage Capital Cost Estimation of Process Design - a Case Study on Biorefinery Design. Front. energy Res. 2015, 3, 1-13. https://doi.org/10.3389/fenrg.2015.00003.

(71) Prinzing, P.; Rod, R.; Aichert, D. Investitionskosten-Schätzung Für Chemieanlagen. Chemie Ing. Tech. 1985, 57 (1), 8-14.

(72) Igos, E.; Benetto, E.; Meyer, R.; Baustert, P.; Othoniel, B. How to Treat Uncertainties in Life Cycle Assessment Studies? Int. J. Life Cycle Assess. 2018. https://doi.org/10.1007/s11367-018-1477-1.

(73) Altunok, T.; Cakmak, T. A Technology Readiness Levels (TRLs) Calculator Software for Systems Engineering and Technology Management Tool. Adv. Eng. Softw. 2010, 41 (5), 769-778. https://doi.org/10.1016/j.advengsoft.2009.12.018.

(74) Nolte, W. L.; Kennedy, B. C.; Dziegiel, R. J. Technology Readiness Level Calculator, US AFRL， aries.ucsd.edu/ARIES/MEETINGS/0712/Waganer/TRL Calc Ver 2_2.xls (accessed Aug 27, 2018). 


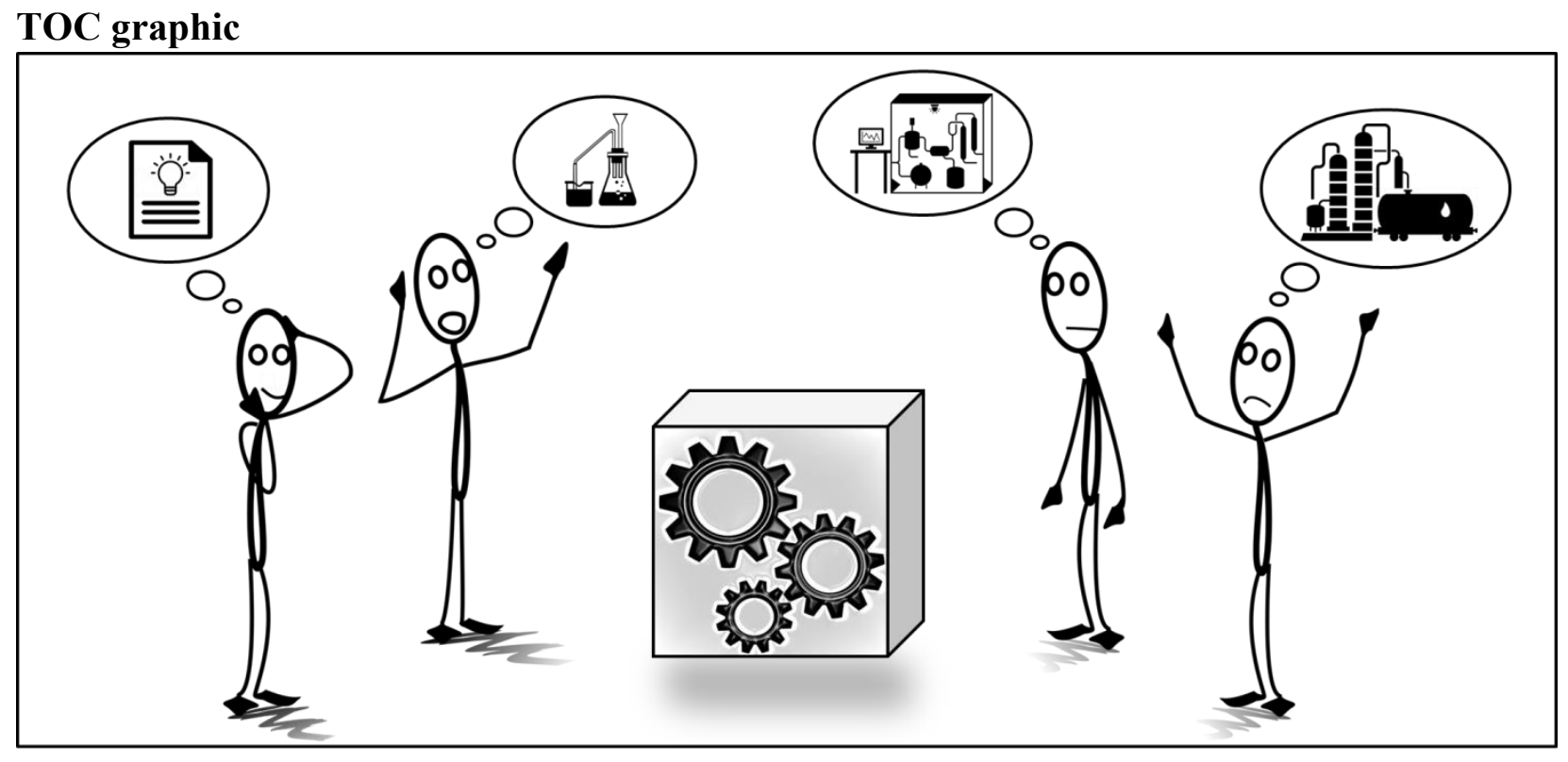

53 